\title{
Evaluation of Tacrolimus Combined With Corticosteroids vs Modified Ponticelli Regimen as Treatments for Refractory Primary Membranous Nephropathy
}

\author{
Elkin Navarro-Quiroz ${ }^{1,2}$, Gustavo Aroca-Martinez ${ }^{1,2}$, Alex Domínguez-Vargas ${ }^{2}$, María José Alonso-López ${ }^{3}$, \\ Rebeca Alvarado-Echeverría ${ }^{2}$, Roberto Navarro-Quiroz ${ }^{4}$, Diana Silva-Díaz ${ }^{2}$, \\ Lorena Gomez Escorcia ${ }^{2}$ \& Henry J. González-Tórres ${ }^{1,2}$ \\ ${ }^{1}$ Facultad de Ciencias Básicas y Biomédicas, Universidad Simón Bolívar, Barranquilla, Atlántico, Colombia \\ ${ }^{2}$ Grupo de nefrología, Clínica de la Costa, Barranquilla, Atlántico, Colombia \\ ${ }^{3}$ Centro Universitario de Tonalá, Universidad de Guadalajara, Jalisco, México \\ ${ }^{4}$ Centro de Investigación en Salud para el Trópico, Universidad Cooperativa de Colombia, Santa Marta, Colombia \\ Correspondence: Elkin Navarro-Quiroz, Facultad de ciencias básicas y biomédicas, Universidad Simón Bolívar, \\ Barranquilla, Atlántico, $\mathrm{Cr} 58$ \# 55-132. Colombia. Tel: 57-301-598-7517. E-mail: \\ enavarro26@unisimonbolivar.edu.co
}

Received: September 22, 2018 Accepted: October 23, 2018 Online Published: November 9, 2018

doi:10.5539/gjhs.v10n12p63 URL: https://doi.org/10.5539/gjhs.v10n12p63

\begin{abstract}
Objective: To evaluate the immunosuppressive treatment response to modified Ponticelli regimen (MPR) and oral corticosteroid (OC) plus tacrolimus (TAC) in patients with primary membranous nephropathy (PMN).
\end{abstract}

Methods: Retrospective cohort analytical study. Adults patients ( $>18$ years old) with diagnosis of refractory PMN $(>50 \%$ increase in serum creatinine or a level $>1.5 \mathrm{mg} / \mathrm{dl}$ or proteinuria refractory to 6 months of supportive treatment), proved by renal biopsy and immunofluorescence between 2008 and 2016 from the Nephropathy Registry of Colombia (NEFROREDC) were included. Immunosuppressive treatment response was evaluated from baseline to 6 months after the start of therapy.

Results: 128 patients with PMN were included, of which 74 (57\%) were female. The most frequent syndromic diagnosis was nephrotic syndrome 90 (70\%), followed by asymptomatic urinary disorders 31 (25\%). Chronic kidney disease manifested concomitantly in $7(5 \%)$ patients. At the end of 6 months, $86(67 \%)$ cases achieved some degree of remission: 23 (18\%) complete response (CR) and 63 (49\%) cases with partial response (PR), while $42(33 \%)$ cases did not achieved remission. In the TAC+OC group, CR and PR were seen in $14(20 \%)$ and $33(47 \%)$ patients, respectively; and $9(16 \%)$ and $30(51 \%)$ patients in the MPR group, respectively. No statistically significant differences were found when comparing the immunosuppressive treatment response rate with both treatment groups $(\mathrm{p}>0.05)$.

Conclusions: In the PMN, both immunosuppressive treatments (TAC+OC vs MPR) are comparable. We suggest a clinical follow-up of the anti-PLA ${ }_{2}$ R/THSD7A titres at $6 / 12$ months to be correlated with renal function in subsequent studies.

Keywords: primary membranous nephropathy, modified Ponticelli regimen, immunosuppressive therapy, tacrolimus

\section{Introduction}

Primary membranous nephropathy $(\mathrm{PMN})$ is an autoimmune glomerular disease that presents with increased proteinuria associated with a pathognomonic "spikes" pattern of injury in glomeruli (Couser, 2017). Most PMN is mediated by antibodies to the M-type phospholipase $\mathrm{A}_{2}$ receptor (anti-PLA $\left.\mathrm{R}\right)(85 \%)$, thrombospondin type 1 domain containing 7A (THSD7A) (3-5\%), or by unidentified mechanisms (10\%) (Cattran \& Brenchley, 2017; De Vriese, Glassock, Nath, Sethi, \& Fervenza, 2017). The renal biopsy is the gold standard for the diagnosis. The electronic microscopy detects subepithelial deposits of IgG resulted from in situ immune complex on the basement membrane (Lai et al., 2015).

The PMN is the main cause of nephrotic syndrome (NS) in nondiabetic adults worldwide, representing up to $37 \%$ 
in most series (Ramachandran et al., 2016). Actually, there is not specific standard therapy for PMN, since it is self-limiting in up to $32 \%$ of cases (Couser, 2017). The initial supportive treatment includes careful blood pressure control, angiotensin-converting enzyme inhibitor/angiotensin receptor blocker therapy, salt restriction, diuretics and a low protein diet to minimize proteinuria and enhance chances of a spontaneous remission (Fervenza et al., 2015).

The Kidney Disease Improving Global outcomes (KDIGO) guideline recommends immunosuppressive treatment in refractory PMN with cyclophosphamide (CTX), chlorambucil, cyclosporine (CSA), tacrolimus (TAC), or rituximab before either evidence of progressive loss of renal function $(>50 \%$ increase in serum creatinine or a level $>1.5 \mathrm{mg} / \mathrm{dl}$ ) or proteinuria refractory to 6 months of supportive treatment (Couser, 2017). The success rated of CSA and TAC based therapy either as monotherapy or combined with low-dose oral corticosteroids (OC) are $75 \%$ and $82-85 \%$, respectively (Ramachandran et al., 2016).

The modified Ponticelli regimen (MPR), includes cyclical therapy of pulse steroids and CTX. This leads to remissions of proteinuria in about $50-60 \%$ of patients at 1 year and a renal survive up to $90 \%$ after a decade of follow up (D. Cattran \& Brenchley, 2017; Ponticelli \& Glassock, 2014). The three most utilized regimens (MPR, $\mathrm{TAC}+\mathrm{OC}$, and rituximab) are similar in lowering anti-PLA ${ }_{2} \mathrm{R}$ levels (D. Cattran \& Brenchley, 2017; De Vriese et al., 2017).

In PMN, the targets of the immunosuppressive treatment would be complete remission (CR) and partial remission (PR) of proteinuria, as valid goals of therapy for therapeutic trials and as surrogate markers of good outcomes (Thompson, Cattran, Blank, \& Nachman, 2015). The aim of this study is to evaluate the immunosuppressive treatment response to TAC plus OC and MPR in patients with PMN.

\section{Method}

\subsection{Study Population}

Retrospective cohort analytical study. Adults patients ( $>18$ years old) with diagnosis of refractory PMN ( $>50 \%$ increase in serum creatinine or a level $>1.5 \mathrm{mg} / \mathrm{dl}$ or proteinuria refractory to 6 months of supportive treatment), proved by renal biopsy and immunofluorescence between 2008 and 2016 from the Nephropathy Registry of Colombia (NEFROREDC) (Aroca-Martínez et al., 2015) were included in this study. Patients on renal replacement therapy or with membranous nephropathy (MN) secondary to paraproteinemias, suggestive malignancies by ultrasonography, positive for anti-nuclear factor, hypocomplementaemia, diabetes mellitus, infection by hepatitis B/C virus and HIV or other secondary causes were excluded. Enrolment of Patients is depicted in Figure 1. The ethics committee of the Clínica de la Costa approved this study.

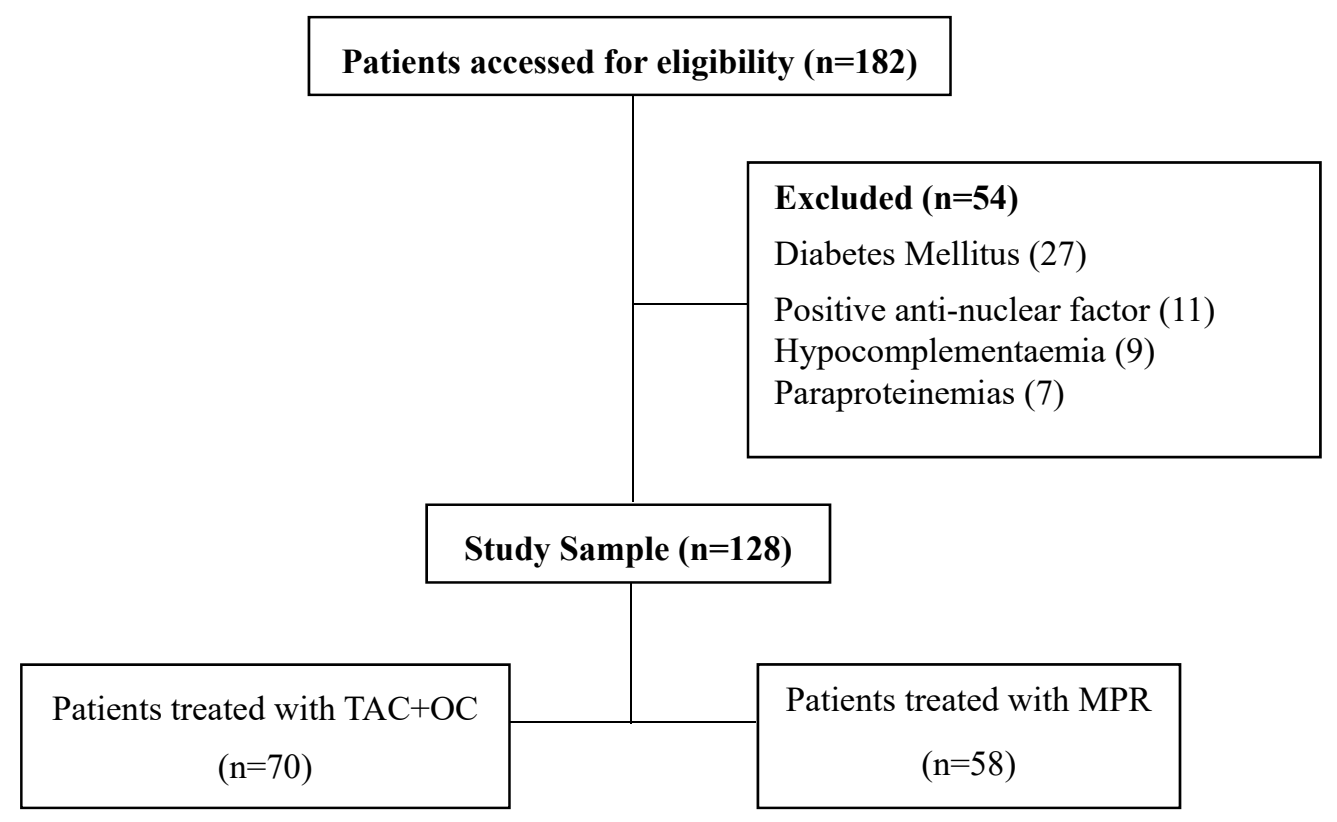

Figure 1. Enrolment of patients and treatments received. TAC: tacrolimus; OC: oral corticosteroids; MPR: modified Ponticelli regimen 


\subsection{Data Collection}

From each medical record, we registered sociodemographic data (age, sex); syndromic diagnosis (nephrotic syndrome, NS; asymptomatic urinary disorders, AUD; chronic kidney disease, CKD); biochemical parameters (serum albumin); renal function (creatinine, 24-hour proteinuria, and estimated glomerular filtration rate, eGFR); type of immunosuppresive treatment (TAC combined with OC or MPR) and type of treatment response (CR;PR; and no remission, NR). Immunosuppressive treatment response was evaluated from baseline to 6 months after the start of therapy.

\subsection{Treatment}

The patients in this study were treated with TAC at a dose of $0.1 \mathrm{mg} / \mathrm{kg}$ in two divided doses per day and oral prednisone was given in a dose of $0.5 \mathrm{mg} / \mathrm{kg} / \mathrm{day}$ and was then gradually reduced to $10 \mathrm{mg} /$ day until the end of 6 months. The MPR consisted of: intravenous methylprednisolone $500 \mathrm{mg}$ /day for three consecutive days, followed by prednisone at a dose of $0.5 \mathrm{mg} / \mathrm{kg} / \mathrm{day}$ for 27 days in the first, third and fifth month and intravenous CTX at a dose of $500 \mathrm{mg} / \mathrm{day}$ per month in the second, fourth, and sixth month. The treating nephrologist established the choice of treatment regimen. All patients received angiotensin-converting enzyme inhibitor or angiotensin receptor blocker therapy at maximum tolerable dose.

\subsection{Definitions and Response Criteria}

Clinical manifestations of patients with PMN were categorized according to the following syndromic diagnoses: NS, defined by proteinuria ( $>3.5 \mathrm{~g} / 24$ hours), edema, and hypoalbuminemia $(<3.5 \mathrm{~g})$; AUD, hematuria, presence of $\geq 5$ red blood cells per field by low power field (lpf) in urine and subnephrotic range proteinuria $(<3.5 \mathrm{~g} / 24$ hours), in the absence of symptoms or signs of kidney disease; and CKD was defined as persistence of an eGFR $<60$ $\mathrm{ml} / \mathrm{min} / \mathrm{m}^{2}$ for more than 3 months.

The patients in this study were classified according to the treatment response criteria of the KDIGO clinical practice guidelines for glomerulonephritis (Kidney Disease Improving Global Outcomes, 2012), in the following response groups: $\mathrm{CR}$, proteinuria $<0.3 \mathrm{~g} / \mathrm{d}$ with stable renal function and normoalbuminemia $(>3.5 \mathrm{~g} / \mathrm{dl})$; $\mathrm{PR}$, reduction $>50 \%$ of basal proteinuria or proteinuria between $0.3 \mathrm{~g} / \mathrm{d}$ and $3.5 \mathrm{~g} / \mathrm{d}$ with stable renal function and normoalbuminemia; and NR, reduction $<50 \%$ of proteinuria or refractory proteinuria $>3.5 \mathrm{~g} / \mathrm{d}$ despite of immunosuppressive treatment.

\subsection{Statistical Analysis}

Sociodemographic and clinical data were analyzed using central tendency and localization measures; Spearman test, multiple correspondence and discriminant analyzes were used to correlate the variables with the treatment response. A two independent proportion test was used to analyze the clinical changes up to 6 months. P-value $<$ 0.05 was considered to be statistically significant. Statistical analysis was done with R project statistical package (R Core Team, 2015).

\section{Results}

A total of 128 patients with refractory PMN were included, of which 74 (57\%) were female. The average age of the patients was $46.05 \pm 14.9$ years. The most frequent syndromic diagnosis was NS 90 (70\%), followed by AUD 31 (25\%). CKD manifested concomitantly in 7 (5\%) patients. The parameters at the start of the immunosuppressive treatment are described in Table 1. No statistically significant differences were found when comparing the baseline parameters between both treatments groups $(\mathrm{TAC}+\mathrm{OC}$ vs MPR). Severe hypoalbuminemia $(<2.5 \mathrm{~g} / \mathrm{dl})$ was evidenced in $53(41 \%)$ cases. 
Table 1. Characteristics at the start of the immunosuppressive treatment

\begin{tabular}{|c|c|c|c|c|}
\hline & $\begin{array}{l}\text { Total } \\
(\mathrm{n}=128)\end{array}$ & $\begin{array}{l}\text { TAC }+ \text { OC } \\
(n=70)\end{array}$ & $\begin{array}{l}\text { MPR } \\
(\mathrm{n}=58)\end{array}$ & p-value \\
\hline \multicolumn{5}{|l|}{ Sociodemographics } \\
\hline Age & $\begin{array}{l}46.05 \pm 14.9 \\
(20-80)\end{array}$ & $\begin{array}{l}46.5 \pm 14.9 \\
(20-83)\end{array}$ & $\begin{array}{l}45.4 \pm 15 \\
(21-82)\end{array}$ & 0.66 \\
\hline Male (\%) & $54(42 \%)$ & $42(60 \%)$ & $32(55 \%)$ & - \\
\hline Female (\%) & $74(57 \%)$ & $28(40 \%)$ & $26(44 \%)$ & - \\
\hline \multicolumn{5}{|l|}{ Renal function } \\
\hline $\begin{array}{l}\text { Serum albumin } \\
(\mathrm{g} / \mathrm{dl})\end{array}$ & $\begin{array}{l}2.69 \pm 0.69 \\
(1.5-4.3)\end{array}$ & $\begin{array}{l}2.66 \pm 0.68 \\
(1.5-4)\end{array}$ & $\begin{array}{l}2.73 \pm 0.7 \\
(1.5-4.3)\end{array}$ & 0.59 \\
\hline $\begin{array}{l}24 \text { h Proteinuria } \\
\text { (g/day) }\end{array}$ & $\begin{array}{l}4.2 \pm 1.6 \\
(0.37-11.6)\end{array}$ & $\begin{array}{l}4.2 \pm 1.5 \\
(1.2-9.3)\end{array}$ & $\begin{array}{l}4.1 \pm 1.9 \\
(0.37-11.6)\end{array}$ & 0.66 \\
\hline $\begin{array}{l}\text { Serum creatinine } \\
(\mathrm{mg} / \mathrm{dl})\end{array}$ & $\begin{array}{l}1.48 \pm 0.59 \\
(0.4-3.5)\end{array}$ & $\begin{array}{l}1.45 \pm 0.53 \\
(0.58-2.92)\end{array}$ & $\begin{array}{l}1.51 \pm 0.66 \\
(0.4-3.5)\end{array}$ & 0.61 \\
\hline $\begin{array}{l}\text { eGFR } \\
(\mathrm{mL} / \mathrm{min} / 1.73 \mathrm{~m} 2)\end{array}$ & $\begin{array}{l}60.6 \pm 32.7 \\
(18.3-155.4)\end{array}$ & $\begin{array}{l}60.5 \pm 31.1 \\
(22-147.3)\end{array}$ & $\begin{array}{l}60.7 \pm 34.8 \\
(18.3-155.4)\end{array}$ & 0.96 \\
\hline \multicolumn{5}{|c|}{ Syndromatic diagnosis } \\
\hline NS (\%) & $90(70 \%)$ & $55(78 \%)$ & $35(60 \%)$ & - \\
\hline AUD (\%) & $31(25 \%)$ & $13(18 \%)$ & $18(31 \%)$ & - \\
\hline CKD (\%) & $7(5 \%)$ & $2(2 \%)$ & $5(9 \%)$ & - \\
\hline
\end{tabular}

NS: nephrotic syndrome; AUD: asymptomatic urinary disorders; CKD: chronic kidney disease; TAC+OC: tacrolimus plus oral corticosteroids; MPR: modified Ponticelli regimen; eGFR: estimated glomerular filtrate rate, calculated by modification of diet in renal disease (MDRD) formula.

\subsection{Outcomes at 6 Month of Treatment}

At the end of the 6 months of treatment, was seen a significant reduction in 24 hours proteinuria (4.2 \pm 1.5 to $2.7 \pm$ 1.6 vs $4.1 \pm 1.9$ to $2.9 \pm 1.8)(\mathrm{p}=0.003 ; \mathrm{p}=0.002)$ and serum creatinine $(1.45 \pm 0.53$ to $1.29 \pm 0.43 \mathrm{vs} 1.51 \pm 0.66$ to $1.27 \pm 0.43)(\mathrm{p}=0.04, \mathrm{p}=0.02)$ in both treatment groups (TAC+OC vs MPR), respectively. An increase in the eGFR was observed in both groups, however, it was not significant $(p=0.27$ vs $p=0.29)$ (Table 2). Albuminuria was reduced in both treatment groups without statistical significance $(p>0.05)$

Tabla 2. Laboratory values at the end of the 6 months of treatment

\begin{tabular}{|c|c|c|c|c|}
\hline Parameters & Treatment & Basal & 6 months & p-value \\
\hline \multirow{4}{*}{$\begin{array}{l}\text { Serum albumin } \\
(\mathrm{g} / \mathrm{dl})\end{array}$} & $\mathrm{TAC}+\mathrm{OC}$ & $2.66 \pm 0.68$ & $2.6 \pm 0.6$ & 0.75 \\
\hline & & $(1.5-4)$ & $(1.4-3.9)$ & \\
\hline & MPR & $2.73 \pm 0.7$ & $2.6 \pm 0.71$ & 0.97 \\
\hline & & $(1.5-4.3)$ & $(1.4-3.9)$ & \\
\hline \multirow{4}{*}{$\begin{array}{l}24 \text { hours Proteinuria } \\
\text { (g/día) }\end{array}$} & $\mathrm{TAC}+\mathrm{OC}$ & $4.2 \pm 1.5$ & $2.7 \pm 1.6$ & 0.003 \\
\hline & & $(1.2-9.3)$ & $(0.1-5.6)$ & \\
\hline & MPR & $4.1 \pm 1.9$ & $2.9 \pm 1.8$ & 0.002 \\
\hline & & $(0.37-11.6)$ & $(0.17-6.8)$ & \\
\hline
\end{tabular}




\begin{tabular}{lllll}
\hline $\begin{array}{l}\text { Serum creatinine } \\
(\mathrm{mg} / \mathrm{dl})\end{array}$ & TAC+OC & $1.45 \pm 0.53$ & $1.29 \pm 0.43$ & 0.04 \\
& & $(0.58-2.92)$ & $(0.7-2.2)$ & 0.02 \\
\cline { 2 - 5 } & MPR & $1.51 \pm 0.66$ & $1.27 \pm 0.43$ & $(0.7-2.2)$ \\
\hline eGFR & & $0.4-3.5)$ & $65.7 \pm 22.8$ & 0.27 \\
$(\mathrm{~mL} / \mathrm{min} / 1.73 \mathrm{~m} 2)$ & TAC+OC & $60.5 \pm 31.1$ & $(23.9-131.4)$ & 0.29 \\
& & $(22-147.3)$ & $65.4 \pm 25.1$ & $(26.7-129.6)$ \\
\end{tabular}

TAC+OC: tacrolimus plus oral corticosteroids; MPR: modified Ponticelli regimen; eGFR: estimated Glomerular Filtrate rate, calculated by modification of diet in renal disease (MDRD) formula.

In relation to the immunosuppressive treatment response. At 6 months, 86 (67\%) cases achieved some degree of remission: 23 (18\%) CR and 63 (49\%) cases with PR, while $42(33 \%)$ cases did not achieved remission. In the TAC + OC group, CR and PR were seen in $14(20 \%)$ and $33(47 \%)$ patients, respectively; and $9(16 \%)$ and $30(51 \%)$ patients in the MPR group, respectively. No statistically significant differences were found when comparing the immunosuppressive treatment response rate with both treatment groups $(p>0.05)$ (Table 3$)$.

Table 3. Clinical response according to treatment group

\begin{tabular}{lllll}
\hline Response & $\begin{array}{l}\text { Total } \\
(\mathrm{n}=128)\end{array}$ & $\begin{array}{l}\text { TAC+OC } \\
(\mathrm{n}=70)\end{array}$ & $\begin{array}{l}\text { MPR } \\
(\mathrm{n}=58)\end{array}$ & p-value \\
\hline Complete Remission $(\%)$ & $23(18 \%)$ & $14(20 \%)$ & $9(16 \%)$ & 0,15 \\
Partial Remission (\%) & $63(49 \%)$ & $33(47 \%)$ & $30(51 \%)$ & 0,17 \\
No Remission (\%) & $42(33 \%)$ & $23(33 \%)$ & $19(33 \%)$ & 0,15 \\
\hline
\end{tabular}

TAC+OC: tacrolimus plus oral corticosteroids; MPR: modified Ponticelli Regimen.

\section{Discussion}

PMN is a kidney-specific, autoimmune glomerular disease characterized by subepithelial immune complex deposits. Formationof perpendicular projections of "spikes" on the glomerular basement membrane (GBM) between the podocyte cytoplasm and the GBM are observed by light microscopy (Ronco \& Debiec, 2010). The anti-PLA ${ }_{2} \mathrm{R}$ and THSD7A may be present in the circulation and also deposited in glomeruli in up to $85 \%$ and $5 \%$ of adults patients with PMN, respectively. Dual expression has been reported as an uncommon event (D. Cattran \& Brenchley, 2017; Tomas et al., 2014).

In PMN, the initiation of antibody response precedes development of proteinuria by weeks or months. Over time, a threshold quantity of IgG4 and membrane attack complex (C5b-9) cause production of oxidants, proteases, growth factors, extracellular matrix components as well as to slit diaphragm, disruption, and podocyte apoptosis which lead to an increase of the urine protein excretion, AUD and NS (Couser, 2017; Francis, Beck, \& Salant, 2016; Ma, Sandor, \& Beck, 2013). In our study, up to $70 \%$ cases evidenced NS followed by AUD in $30 \%$ cases.

It is well known that the classic predictive risk factors for kidney damage in PMN include female sex, advanced age, proteinuria levels, as well as impaired renal function at the beginning of the study (Couser, 2017). In the present study, all these parameters were similar between the two treatment groups.

The treatment of PMN is a topic under discussion among health professionals (Gaviria-García et al., 2015; Sierra, 2017), traditional approaches to treatment of PMN begin with supportive treatment alone and withhold immunosuppressive treatment until the patients meets criteria that predict progression towards renal failure (D. C. Cattran \& Brenchley, 2017b; Ronco \& Debiec, 2010). Other different situations to those described in this study that would dictate early initiation of immunosuppresive treatment are proteinuria $>10 \mathrm{~g} /$ day and complications of the NS as anasarca, thromboembolic events or unexplained loss of eGFR (Couser, 2017).

In the present study, a remission rate of $67 \%$ was achieved at the end of 6 months in both treatment groups 
(TAC+OC and MPR) which is lower than previously reported studies and it is likely due we included only patients with refractory PMN. (Ponticelli et al., 1998) reported an initial remission rate of $93 \%$ with CR and PR in $37 \%$ and $56 \%$, respectively, with the MPR in 87 cases of PMN. In a clinical trial to evaluate the immunosuppressive treatment in refractory PMN, (He et al., 2013), reported a remission rate of $64 \%$ with MPR in a similar way to our results. Advantages of the MPR include the well-established efficacy, including reduction in CKD, lower relapse rate $(25 \%)$ and long-term experience with its use. Some disadvantages include a relatively high adverse event rate (25\%): infertility, later malignancy, infection, and need for close monitoring of hematologic parameters (Aldana, Diazgranados, Aroca, \& García, 2014; Das, Dakshinamurty, \& Prasad, 2009)

TAC used either as monotherapy or combined with low-dose OC, have been shown to decrease proteinuria, reduce the rate of loss of renal function and decrease anti-PLA ${ }_{2} \mathrm{R}$ levels (D. Cattran \& Brenchley, 2017; De Vriese et al., 2017). (He et al., 2013), reported a remission rate of $65 \%$ in the TAC group from a randomized 100 cases of PMN. At the end of 6 month, (Chen et al., 2010), concluded that $85 \%$ of the patients in the TAC group achieved remission and (Ramachandran et al., 2016), reported a remission rate of $74 \%$ in the TAC group from 70 cases of refractory PMN. In the present study the response to TAC was less, it could be hypothesized that perhaps the particular ethnic mixture of the region, composed by European, African and indigenous ancestors, could lead to a particular clinically aggressive profile compared to other areas.

The main limitation in our study is we did not measure the anti-PLA ${ }_{2} \mathrm{R} / \mathrm{THSD} 7 \mathrm{~A}$ titres in the PMN cases. All adult patients with PMN and NS should be screened initially for anti-PLA 2 R/THSD7A. Observational correlations between the anti-PLA ${ }_{2} \mathrm{R} / \mathrm{THSD} 7 \mathrm{~A}$ pathogenic mechanisms described above and its importance to the clinical decision-making as renal function predictor markers (Couser, 2017; Tomas et al., 2014) now support incorporating anti-PLA $\mathrm{A}_{2} \mathrm{R} / \mathrm{THSD} 7 \mathrm{~A}$ in subsequent studies.

In conclusion, In the PMN, both immunosuppressive treatments (TAC+OC vs MPR) are comparable. We suggest a clinical follow-up of the anti-PLA ${ }_{2} \mathrm{R} / \mathrm{THSD} 7 \mathrm{~A}$ titres at $6 / 12$ months to be correlated with renal function in subsequent studies.

\section{Acknowledgments}

All the authors approved the final manuscript and agreed to its publication. The authors declare no grants in this study

\section{Competing Interests Statement}

The authors declare that there are no competing or potential conflicts of interest.

\section{References}

Aldana, I., Diazgranados, I., Aroca, G., \& García, R. (2014). Respuesta al esquema Ponticelli en pacientes con nefropatía membranosa idiopática. Barranquilla 2011-2013. Biociencias, 9(1), 23-29.

Aroca-Martínez, G., Depine, S., Consuegra-Machado, J. R., González-Torres, H. J., Árquez-Mendoza, M., \& Estrada-García, E. (2015). Development and use of an application programming interface modified from GoogleMaps $\odot$ for the georeferencing of patients with glomerular disease. Nefrología : Publicación Oficial de La Sociedad Española Nefrologia, 35(1), 118-120. https://doi.org/10.3265/Nefrologia.pre2014.Oct.12736

Cattran, D., \& Brenchley, P. (2017). Membranous nephropathy: thinking through the therapeutic options. Nephrology Dialysis Transplantation, 32(suppl_1), i22-i29. https://doi.org/10.1093/ndt/gfw404

Cattran, D. C., \& Brenchley, P. E. (2017a). Membranous nephropathy: integrating basic science into improved clinical management. Kidney International, 91(3), 566-574. https://doi.org/10.1016/j.kint.2016.09.048

Chen, M., Wang, H.-Y., Li, H., Li, X.-W., Li, X.-Y., Chen, J.-H., ... Xu, F.-F. (2010). Tacrolimus Combined With Corticosteroids in Treatment of Nephrotic Idiopathic Membranous Nephropathy: A Multicenter Randomized Controlled Trial. The American Journal of the Medical Sciences, 339(3), 233-238. https://doi.org/10.1097/MAJ.0b013e3181ca3a7d

Couser, W. G. (2017). Primary membranous nephropathy. Clinical Journal of the American Society of Nephrology, 12(6), 983-997. https://doi.org/10.2215/CJN.11761116

Das, U., Dakshinamurty, K., \& Prasad, N. (2009). Ponticelli regimen in idiopathic nephrotic syndrome. Indian Journal of Nephrology, 19(2), 48. https://doi.org/10.4103/0971-4065.53321

De Vriese, A. S., Glassock, R. J., Nath, K. A., Sethi, S., \& Fervenza, F. C. (2017). A Proposal for a Serology-Based Approach to Membranous Nephropathy. Journal of the American Society of Nephrology, 28(2), 421-430. https://doi.org/10.1681/ASN.2016070776 
Fervenza, F. C., Canetta, P. A., Barbour, S. J., Lafayette, R. A., Rovin, B. H., Aslam, N., .. Cattran, D. C. (2015). A Multicenter Randomized Controlled Trial of Rituximab versus Cyclosporine in the Treatment of Idiopathic Membranous Nephropathy (MENTOR). Nephron, 130(3), 159-168. https://doi.org/10.1159/000430849

Francis, J. M., Beck, L. H., \& Salant, D. J. (2016). Membranous Nephropathy: A Journey From Bench to Bedside. American Journal of Kidney Diseases, 68(1), 138-147. https://doi.org/10.1053/j.ajkd.2016.01.030

Gaviria-García, G., Turizo, L., Orostegui, M., Suárez-Villa, M., Rivera-Julio, Y., Villalba, A., ... Navarro-Díaz, L. (2015). Evaluacion del aprendizaje en enfermería: una mirada desde la asignatura del area profesional. In Educación: Una Mirada Desde La Comunicación, La Tecnología, La Investigación Y La Didactica (pp. 145-147). Colombia,: ed: Corporación Universitaria Americana.

He, L., Peng, Y., Liu, H., Liu, Y., Yuan, S., Liu, F., ... Fu, M. (2013). Treatment of idiopathic membranous nephropathy with combination of low-dose tacrolimus and corticosteroids. Journal of Nephrology, 26(3), 564-571. https://doi.org/10.5301/jn.5000199

Lai, W. L., Yeh, T. H., Chen, P. M., Chan, C. K., Chiang, W. C., Chen, Y. M., ... Tsai, T. J. (2015). Membranous nephropathy: A review on the pathogenesis, diagnosis, and treatment. Journal of the Formosan Medical Association, 114(2), 102-111. https://doi.org/10.1016/j.jfma.2014.11.002

Ma, H., Sandor, D. G., \& Beck, L. H. (2013). The Role of Complement in Membranous Nephropathy. Seminars in Nephrology, 33(6), 531-542. https://doi.org/10.1016/j.semnephrol.2013.08.004

Ponticelli, C., Altieri, P., Scolari, F., Passerini, P., Roccatello, D., Cesana, B., ... Bellazzi, R. (1998). A randomized study comparing methylprednisolone plus chlorambucil versus methylprednisolone plus cyclophosphamide in idiopathic membranous nephropathy. Journal of the American Society of Nephrology: JASN, 9(3), 444-450. Retrieved from http://www.ncbi.nlm.nih.gov/pubmed/9513907

Ponticelli, C., \& Glassock, R. J. (2014). Glomerular Diseases: Membranous Nephropathy--A Modern View. Clinical Journal of the American Society of Nephrology, 9(3), 609-616. https://doi.org/10.2215/CJN.04160413

R Core Team. (2015). R: A Language and Environment for Statistical Computing. Vienna, Austria: R Foundation for Statistical Computing.

Ramachandran, R., Hn, H. K., Kumar, V., Nada, R., Yadav, A. K., Goyal, A., ... Kohli, H. S. (2016). Tacrolimus combined with corticosteroids versus Modified Ponticelli regimen in treatment of idiopathic membranous nephropathy: Randomized control trial. Nephrology, 21(2), 139-146. https://doi.org/10.1111/nep.12569

Ronco, P., \& Debiec, H. (2010). Antigen identification in membranous nephropathy moves toward targeted monitoring and new therapy. Journal of the American Society of Nephrology: JASN, 21(4), 564-569. https://doi.org/10.1681/ASN.2009121220

Sierra, C. (2017). Calidad de vida en pacientes con enfermedad renal crónica de una institución de salud. In Estudios actuales en Psicología. Perspectivas en Clinica y Salud (pp. 71-93. ISBN: 978-958-8930-68-8). Colombia: ed: Editorial Mejoras.

Thompson, A., Cattran, D. C., Blank, M., \& Nachman, P. H. (2015). Complete and Partial Remission as Surrogate End Points in Membranous Nephropathy. Journal of the American Society of Nephrology, 26(12), 2930-2937. https://doi.org/10.1681/ASN.2015010091

Tomas, N. M., Beck, L. H., Meyer-Schwesinger, C., Seitz-Polski, B., Ma, H., Zahner, G., ... Lambeau, G. (2014). Thrombospondin Type-1 Domain-Containing 7A in Idiopathic Membranous Nephropathy. New England Journal of Medicine, 371(24), 2277-2287. https://doi.org/10.1056/NEJMoa1409354

\section{Copyrights}

Copyright for this article is retained by the author(s), with first publication rights granted to the journal.

This is an open-access article distributed under the terms and conditions of the Creative Commons Attribution license (http://creativecommons.org/licenses/by/4.0/). 